\title{
The Astro Spiral Jump- An Automobile Stunt Designed via Computer Simulation
}

\author{
Raymond R. McHenry \\ Calspan Corp.
}

THE DESIGN OF the Astro Spiral Jump was an unusual project for the Calspan Corporation. The end product, a spectacular automobile maneuver, was first publicly performed in the Houston Astrodome (Figure 1) and more recent $1 y$ was featured in the 1974 James Bond film, "The Man with the Golden Gun", produced by United Artists Corporation (Figure 2). It is currently being featured in the American Thrill Show, produced by J. M. Productions, Inc., of Hamburg, New York (1). * In addition to creating a thrill show feature act, this project has also served to substantially extend the response ranges of the validation of the computer simulation used in its design.

The HVOSM computer simulation of automobi le dynamics (i.e. , Highway Vehicle Obstacle Simulation Model, (2)) was developed by Calspan for applications related to the safety aspects of highway and roadside design. This digital program in the Fortran IV

\footnotetext{
Numbers in parenthesis designate References at end of paper.
}

language has been rigorously validated for a wide variety of vehicle maneuvers, including the upper limits of vehicle control and collisions with obstacles, and it is currently being used in highway safety applications by Calspan and by more than fifty recipients of copies of the program.

In this paper, the rationale for development of the HVOSM program is presented and the general analytical approach of the simulation is briefly described prior to a detailed discussion of the subject application.

Rationale for Development of HVOSM Program - The need for analytical capabilities in highway safety research becomes apparent when one considers the large number of variables that influence both the occurrence and the consequences of highway accidents. Actual accidents include an infinite variety of combinations of direction, speed, evasive maneuvers, obstacles, vehicle and terrain properties, vehicle occupancy and conditions of occupant restraint. Thus, a rigorous evaluation of the benefits to be achieved by
An unusual application of a computer simulation of automobile dynamics to the design of a thrill show stunt is described. The rationale for development of the si mulation for highway safety applications is discussed and the general analytical approach is described. Computer graphics displays of simulation outputs, consisting of detailed perspect ive drawings of the vehicle and terrain features or obstacles at selected intervals of ti me during a simulated maneuver, are presented. For the presentation of the paper, computer graphics displays of simulation outputs will be animated through the use of motion picture film. Also, motion picture coverage of both developmental tests and public performances of the Astro Spiral Jump will be shown. 


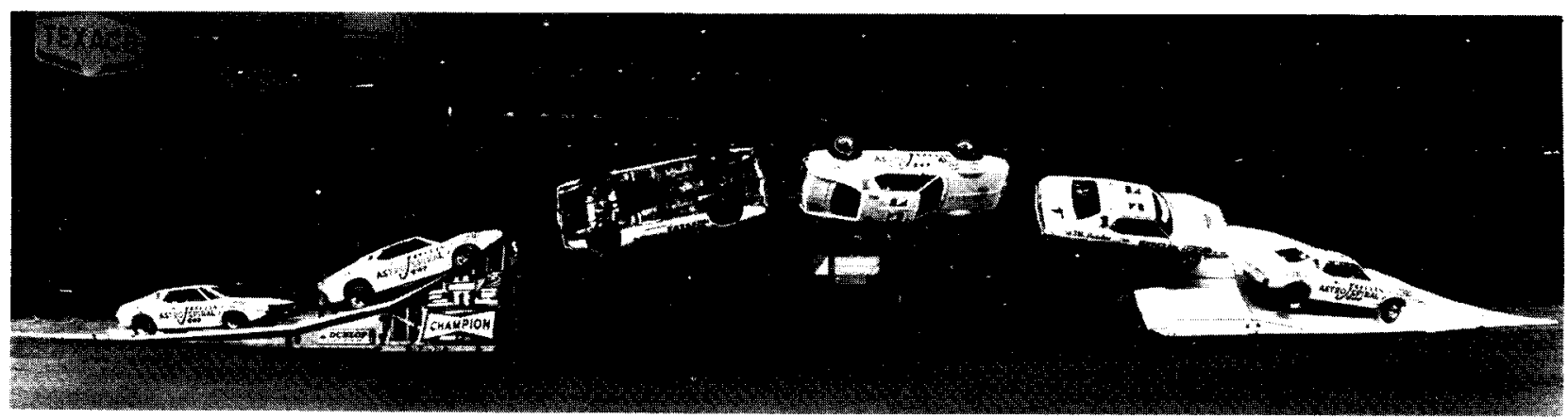

Fig. 1-The astro spiral jump (Houston Astrodome, January 1972)

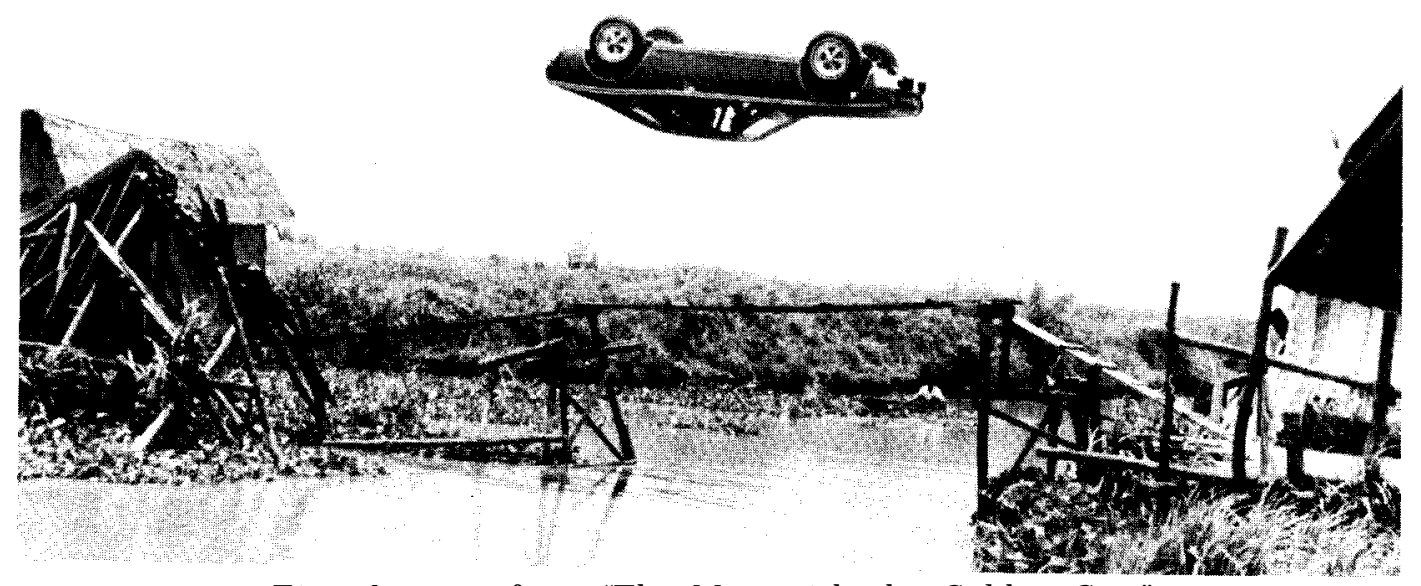

Fig. 2-Scene from "The Man with the Golden Gun",

United Artists Corp, 1974

a given change in vehicle or roadside design must include consideration of a representative sample of vehicles, operating conditions, occupancy and occupant restraints.

In an experimental evaluation, the generally poor repeatability (i.e., the scatter in results) makes it necessary to include several runs of each test condition.

Obviously, a purely experimental evaluation procedure is both time consuming and expensive. Moreover, experiments do not provide a capability of predicting responses of a complex, nonlinear system.

Validated analytical procedures can serve to reduce the required number of tests by providing a means of interpolating experimental results for widely spaced test conditions. They can also serve to provide a predictive capability and, thereby, a theoretical framework within which tests can be planned and experimental data interprcted. The highly nonlinear nature of the physical system both in violent evasive maneuvers and in collisions, demands that realistic analytical procedures be programmed for computer solution. The development and application of such computer simulations are playing an increasingly important role in highway safety research.

Analytical Approach of the Simulation An extensive body of literature exists on analytical studies of automobile dynamics, but the general approach has involved separate treatment of motions in the longitudinal plane (ride responses, performance and braking) and motions in the lateral plane (cornering behavior and stability). Furthermore, the equations of motion have generally been linearized. While such practices are acceptable in studies of small disturbance handling qualities, they are not appropriate for violent maneuvers at the upper limits of vehicle control.

In view of the extended requirements for a realistic analysis of vehicle dynamics in near-accident and accident situations, where interactions between ride and cornering 


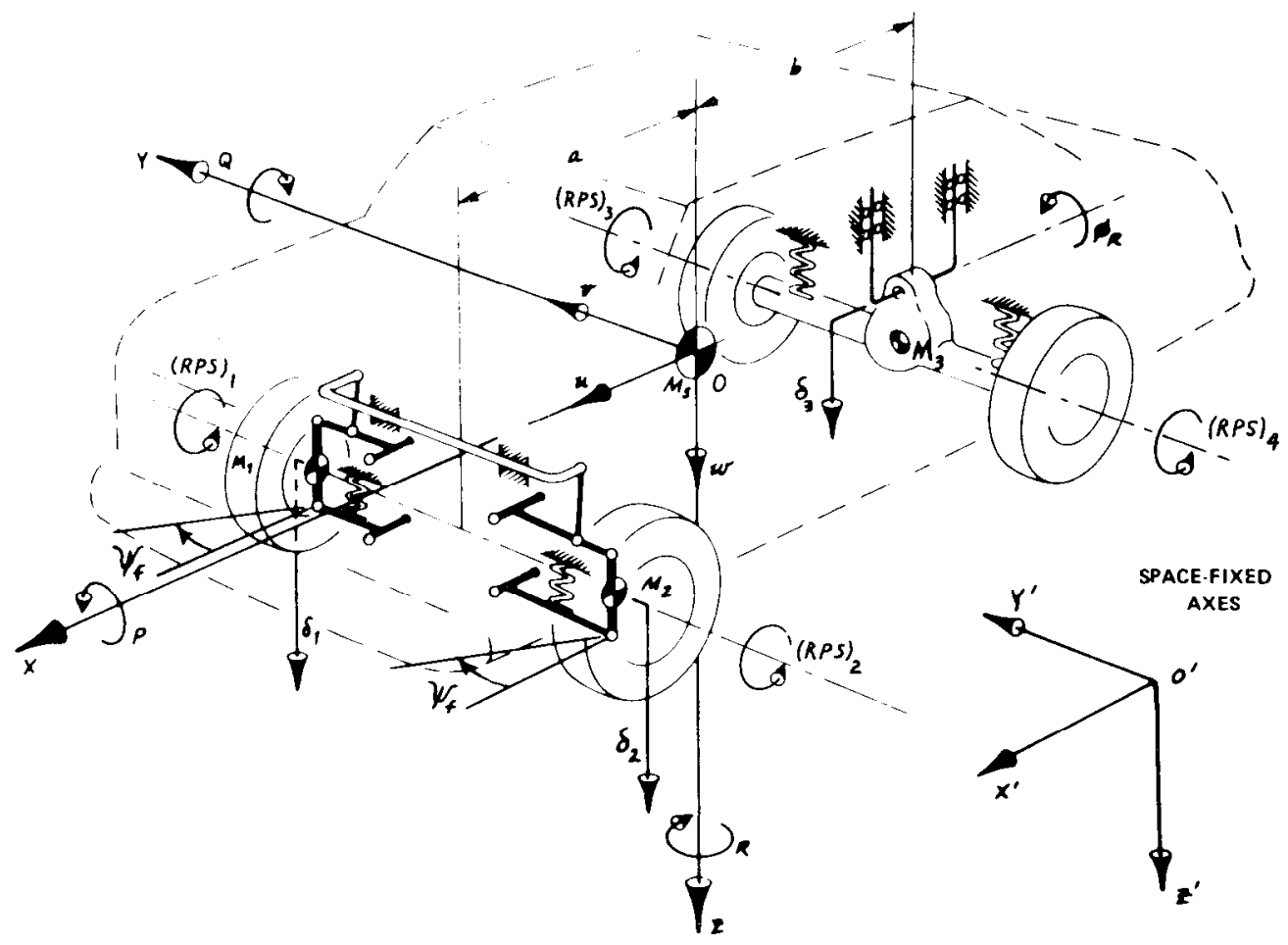

Fig. 3-Analytical representation of vehicle

motions cannot be neglected, the nonlinear HVOSM computer simulation of automobile dynamics has been developed by Calspan to permit the study of simultaneous, large amplitude ride and cornering motions and to include an approximate treatment of collision forces.

The HVOSM vehicle representation (Figure 3) has fifteen degrees of freedom. A major departure from earlier analytical treatments of vehicles is the abandonment of the concept of a fixed roll axis to permit the inclusion of ride motions while cornering.

Two modes of simulation are used for the radial properties of the tires (Figure 4). The first is used when the terrain undulations are sufficiently gradual to produce essentially a planar tire-terrain contact patch at each tire. Within this mode a point contact representation of the tire is used. The second mode is used for cases in which the tire-terrain contact is not planar; here the tires are represented by discs of nonlinear radial springs. The two modes are adjusted to be compatible on a flat surface. In each mode, a "hardening" spring is simulated, the load-deflection curve steepening after a particular deflection is reached.

Tire side forces are generated according to further equations allowing for saturation to occur at large slip angles. The "friction ellipse" concept (Figure 5) is used to simulate the effects of braking and traction on the side forces (3). The simulated suspension forces include progressively stiffening, energy dissipating limit stops and a combi-

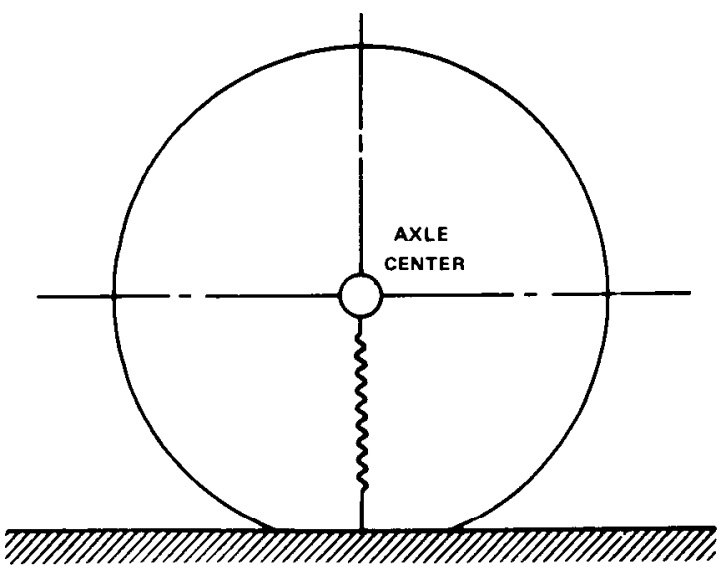

POINT.CONTACT MODEL OF TIRE

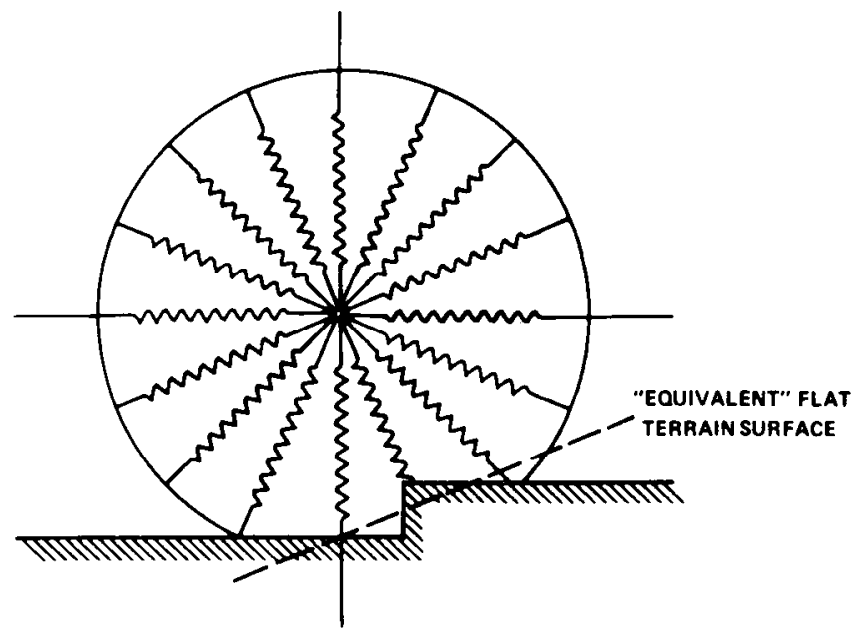

DISTRIBUTED.CONTACT RADIAL SPRING MODEL OF TIRE

Fig. 4-Two modes of simulation of radial characteristics of tires 

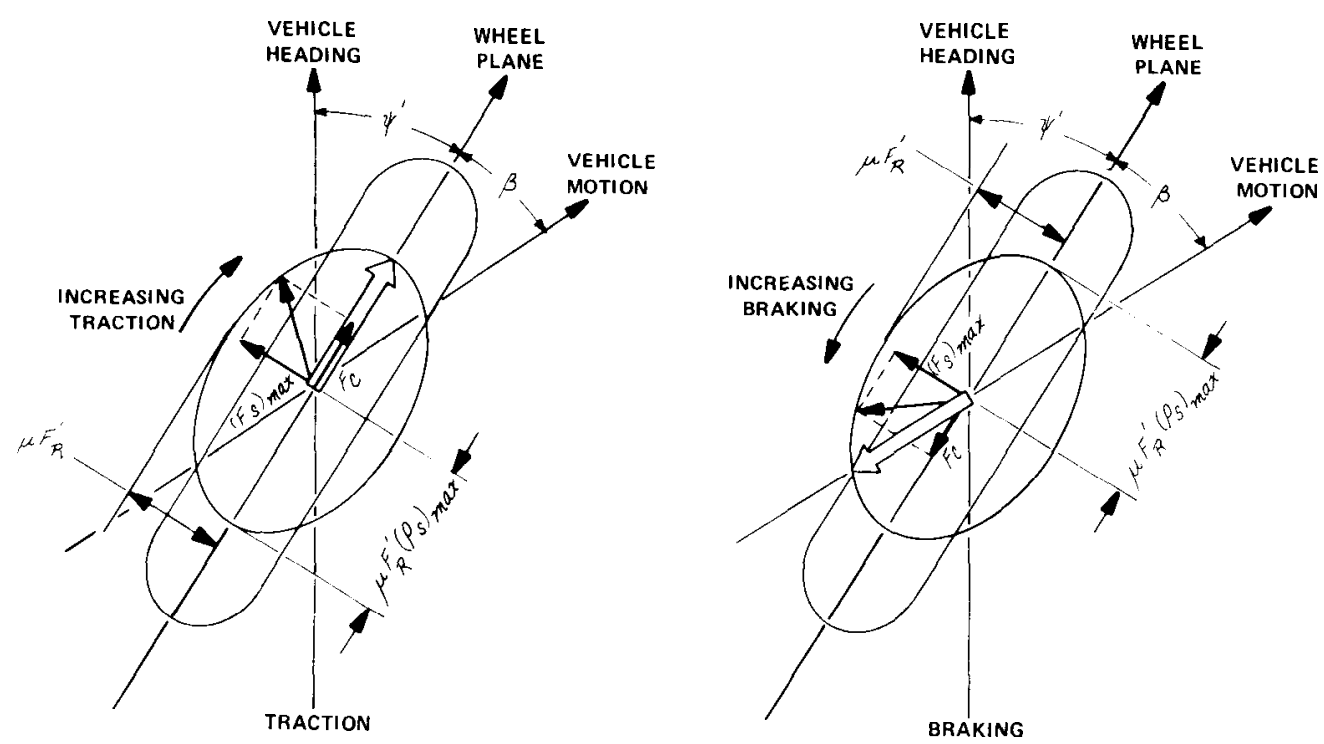

Fig. 5-Friction ellipse concept

nation of coulomb and viscous damping. The terrain is defined by means of tabular entries of the elevations of a large number of points on the terrain surface. These values are interpolated to obtain elevations and slopes at the individual tires.

The steer angle is treated in two modes. It is entered as a tabular function of time but becomes a degree of freedom when either of the front wheels hits an obstacle. This form of simulation allows the steering system to respond to external forces. Traction and braking torques are also entered as tabular functions of time. Preliminary development has also been performed on a closed loop subroutine to simulate the driver and thereby generate evasive driver control inputs in response to the sensory cues.

The sprung mass is represented as a rigid body with a peripheral layer of homogeneous, isotropic, deformable material. The assumed properties of the peripheral layer, with dynamic pressure directly proportional to depth of penetration, are based on the results of dynamic and static crush tests of automobi le structures.

A computer graphics display of the simulated vehicle behavior has been developed in order to ease the task of interpreting the rather extensive output information. The display is produced either on an XY plotter or on a cathode ray tube. The display technique has been developed to produce detailed perspective drawings of the vehicle and terrain, or obstacle, as seen from selected viewing positions and at selected intervals of time during a simulated maneuver or collision (Figure 6). Such a display has been found to be extremely valuable as an aid for program development, for understanding the complex motions and for presenting results. A recent development in the Calspan graphics display is an option to show tracks in broken lines for rolling wheels and solid lines for sliding wheels. This is considered to be particularly valuable for studies related to accident reconstruction. Computer generated motion pictures of the simulated responses have also been produced by means of a flying spot scanner which traces the vehicle's computed position and orientation with a dot of light on a cathode ray tube, a new position being computed for each frame.

The acceptance of computer simulation techniques has been found to be greatly enhanced by the use of computer graphics. Some researchers in the field of highway safety have a tendency to view experiments, whether part or full scale, as being more real and believeable than analyses. At least part of this tendency stems from the fact that physical experiments can be seen and photographed. The computer graphics displays help in allowing the direct observation of computer "experiments".

In actuality, many physical experiments are poorly defined and controlled. Instrumentation errors someti mes yield individual items of response that are not compatible with each other. For example, in the series of physical experiments that were performed to validate the described vehicle simulation, a number of instrumentation difficulties were revealed by the comparisons with analytically predicted results. It is not intended to suggest that computer simulation can ever eliminate the need for physical experiments. Rather, the intention is merely to point out the fact that computer simulations can serve as valuable aids for interpreting the results of physical experiments with nonlinear systems, as well as for interpolation and extrapolation to other combinations of test conditions. 

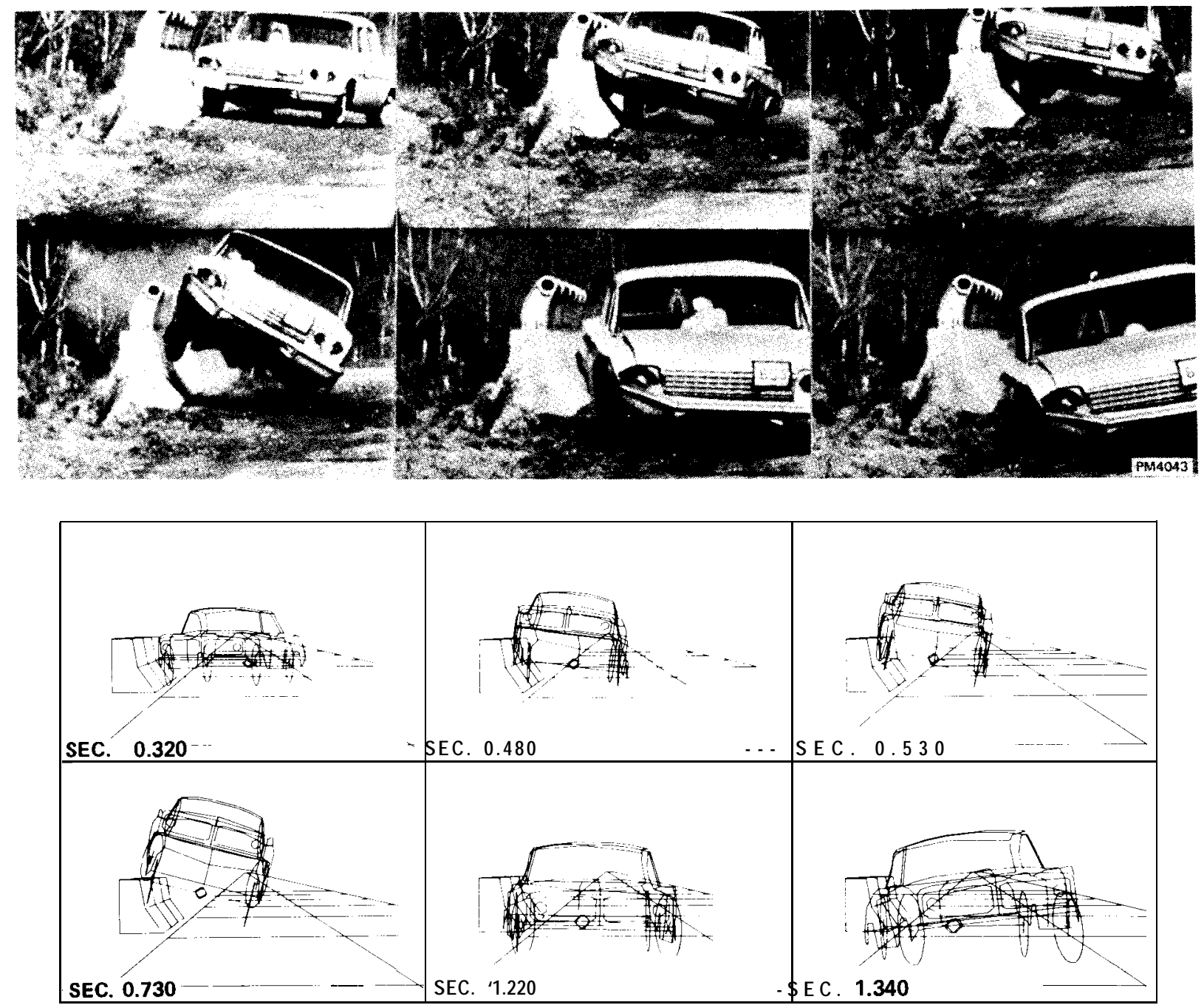

Fig. 6-Experimental and predicted vehicle responses for a $50 \mathrm{mph}, 12 \mathrm{deg}$. collision with the General Motors bridge parapet

The Astro Spiral Jump Application - As a part of the HVOSM development process, Calspan employed the services of professional stunt drivers in 1968 to perform maneuvers and stunts with an instrumented vehicle and, thereby, to generate vehicle response data in violent maneuvers for use in investigating the validity of the computer simulation (e.g., Figure 7). One of the included stunts was a fifty foot jump from a take-off to a receiving ramp (Figure 8 ). The degree of achieved correlation between analytical predictions and experimental measurements was found to be remarkably good in all of the included maneuvers and stunts (4). At the time, it was jokingly pointed out that Calspan had unintentionally developed a capability for the design and staging (i.e., via animated perspective displays on motion picture film) of auto thrill shows. A related, "far out" suggestion was the design of ramps to produce a combination of jump and rollover (i.e., a "spiral" jump), such that the stunt car would land on its wheels after passing over an obstacle in an inverted condition.

Subsequent to completion of development and validation of the HVOSM simulation in 1970 , the thrill show ideas were given somewhat more serious consideration. Such an application would constitute both a challenging dynamics problem, similar in nature to a particularly violent singlevehicle accident, and an attention-getting demonstration of Calspan capabilities. It also had the appeal of a "fun" project to relieve a steady diet of crash protection studies.

In November of 1970 the author contacted Mr. W. J. Milligar, Jr., President, J. M. Productions, Inc., of Hamburg, New York, regarding his possible interest in the design of a new auto thrill show stunt and/or the establishment of speed and dimensional tolerances for existing stunts. The occasion 

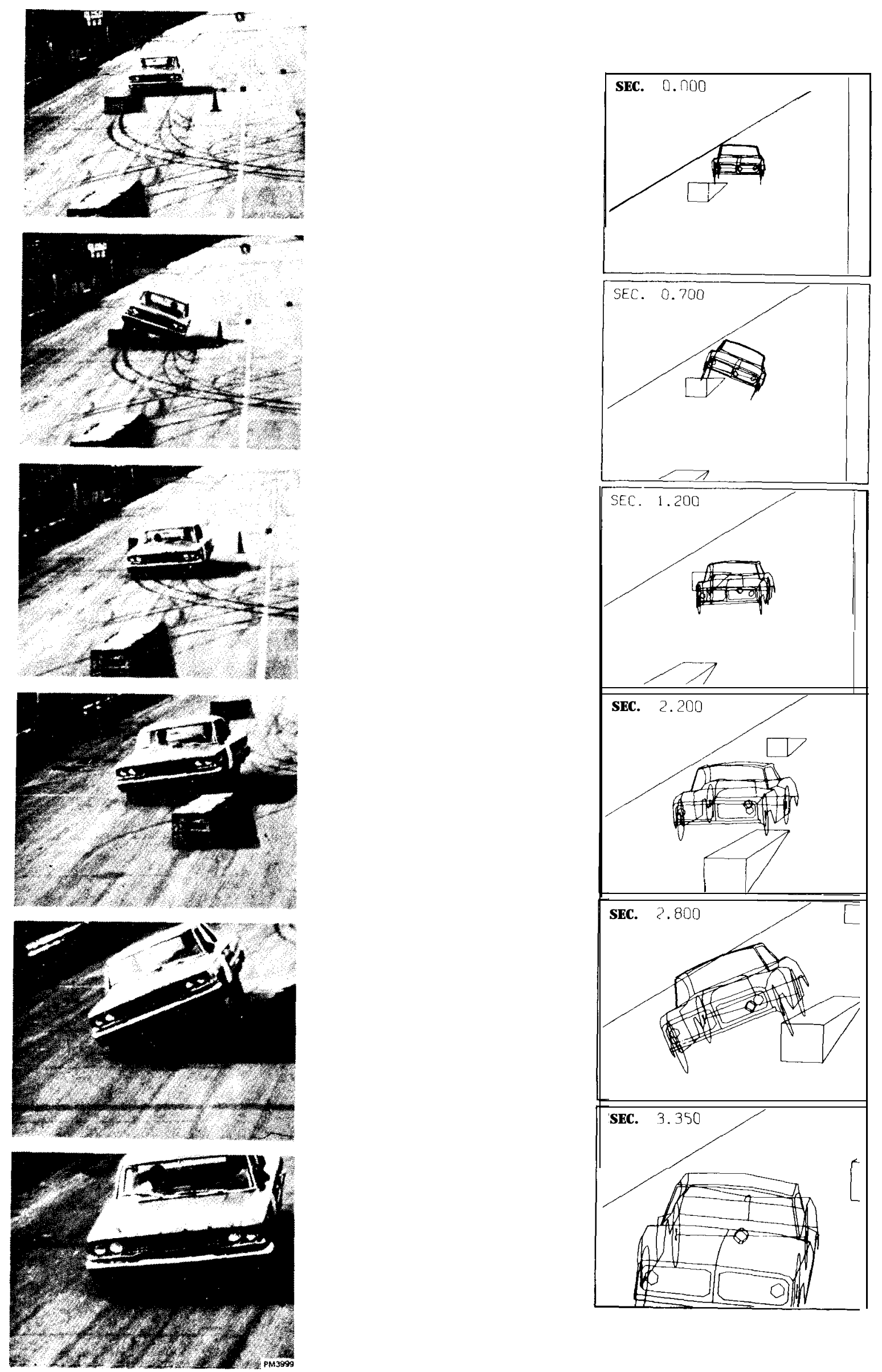

Fig. 7-Alternate ramp traversal at $30 \mathrm{mph}$ 

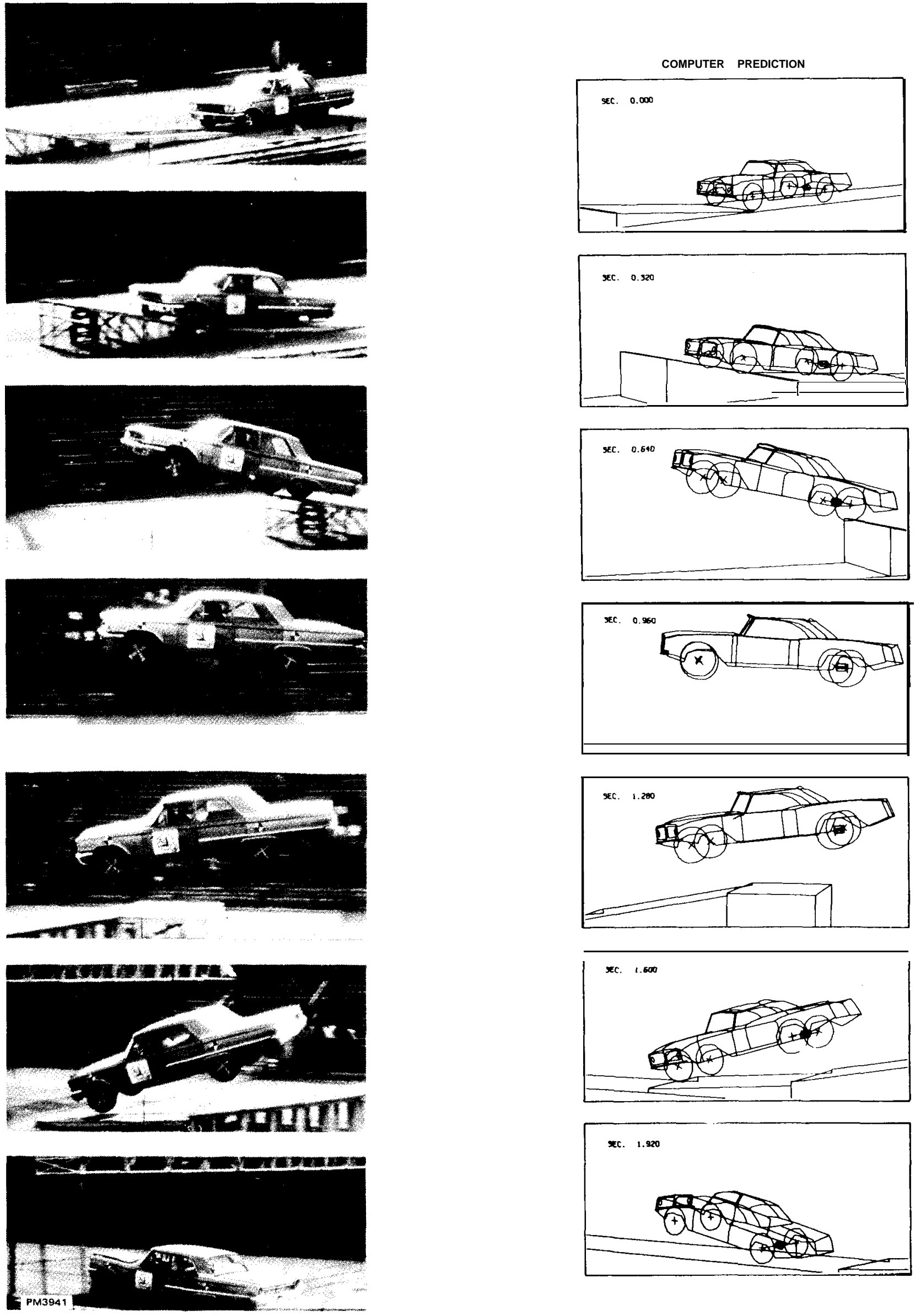
EXPERI MENT

COMPUTER PREDICTION
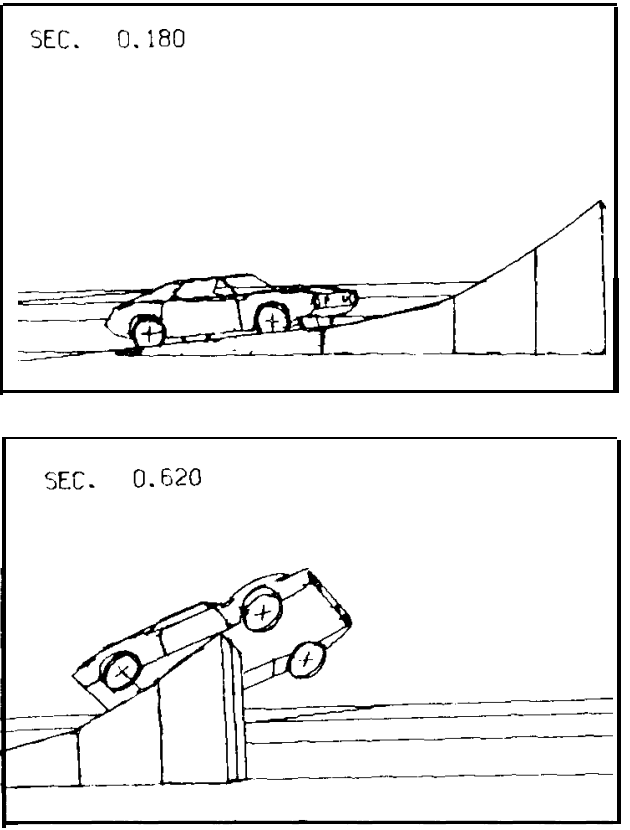

SE 1.260
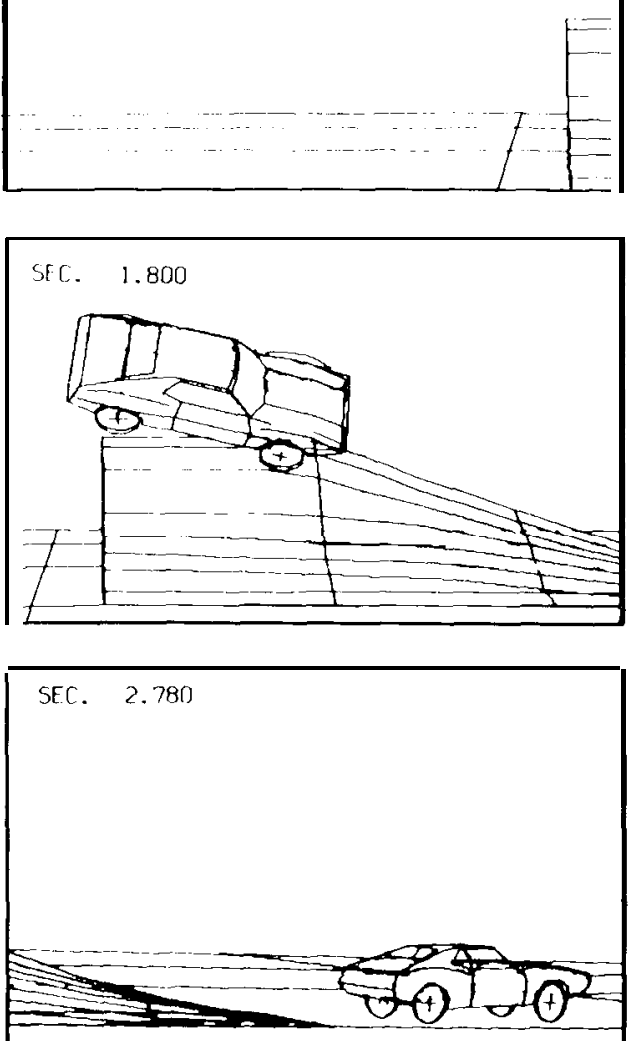
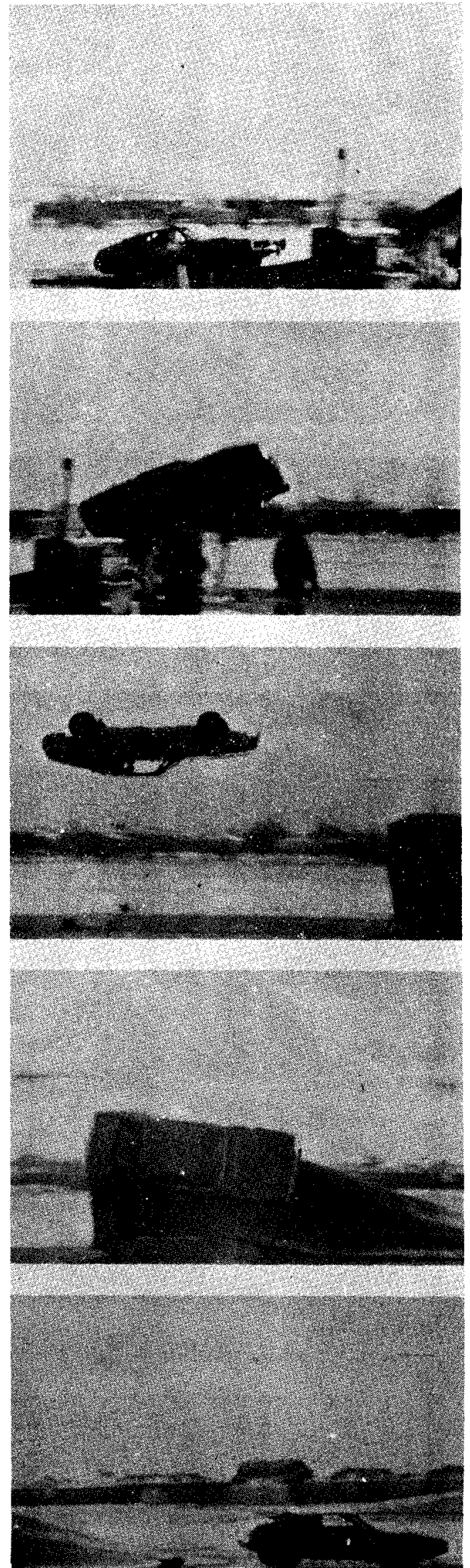

I'ig. 9-predicted and experimental vehicle responses in astro spiral jump 
of the contact was a newspaper item about Mr. Milligan's organization of a new national auto thrill show. As a result of subsequent discussions, J. M. Productions gave Calspan a purchase order to support an analytical study of the spiral jump stunt concept.

The HVOSM simulation does not, of course, provide direct guidance for invention. Its application is equivalent to performing experiments with a fully instrumented vehicle. Therefore, the analytical study of the spiral jump stunt concept consisted essentially of a trial and error process of exploratory changes in ramp configurations.

The initial simulation study indicated that the combined needs to run both ends of the automobile over the same ramp profile in sequence and to generate a large roll acceleration in the $40 \mathrm{MPH}$ speed range would create a serious problem in achieving acceptable pitch and yaw behavior. The limitation to the speed range of $40 \mathrm{MPH}$, which is based on space restrictions that generally exist for thrill show performances, produced a corresponding limitation on the time in the air that was available for the 360 degree rollover. Thus, a large roll velocity (approximately 230 degrees per second) had to be generated to achieve a "wheels down" landing on the receiving ramp. The sequential traversal of the take-off ramp by the front and the rear wheels, when combined with the nonlinear suspension characteristics during the traversal (i.e., front suspension "bottomed out" throughout the roll impulse) was found to create a response sequence in which the rear wheels cleared or only lightly touched the "roll-impulse" end of the ramp. As a result of this sequence, the initially predicted responses retained a "nose-up" attitude during the entire jump and were found to include excessive yawing.

Attempts to achieve a corrective pitch impulse at either of the rear wheels were unsuccessful. The rear wheel that was moving up fastest cleared any ramp configuration that the "bottomed out" front suspension had traversed. An impulse sufficient for the desired pitch response, when applied at the other rear wheel, acted to excessively reduce the roll velocity. Therefore, it became necessary to consider minor vehicle modifications to achieve the desired combination of linear and angular velocities at the end of the take off ramp.

The necessary vehicle modification consisted of an auxiliary contact point on the rear axle, for which the primary loading occurred on the last ten feet of the take-off ramp. The additional contact on the rear axle was also found to require a relatively low side-force capability to avoid unwanted yaw accelerations.
The addition of a ramp contact point on the rear axle was simulated with the computer program and, subsequent to corresponding adjustments of the ramp profile and of its friction properties in the region of contact of the axle contact point, it was demonstrated that acceptable combinations of roll, pitch and yaw behavior could be achieved. A total of 33 exploratory computer runs were involved in this demonstration of feasibility.

The receiving ramp configuration was found to be somewhat less critical, in view of the continuous corrections generated by the wheel contact forces. However, the takeoff had to generate a sufficiently accurate combination of linear and angular velocities that the vehicle would make an acceptable landing approach after approximately 1.5 seconds of flight. A total of 12 computer runs were required to achieve a successful configuration for the receiving ramp.

The ramp configurations and the minor vehicle modification were defined directly by the corresponding inputs to the HVOSM computer program in the successful runs (5). The structural design of the take-off and receiving ramps made direct use of predicted dynamic loading information.

Initial experimental runs were performed using a wire-following steering system and an automatic speed control. A comparison of predicted and experimental vehicle responses, for the first experimental run, is presented in Figure 9.

\section{CONCLUDING REMARKS}

The overall complexity of the threedimensional vehicle responses in the Astro Spiral Jump make it virtually impossible to predict behavior by means other than the HVOSM computer program. Also, the destructive aspects of unsuccessful tests would preclude the application of a "trial and error" experimental development. Thus, the computer simulation constitutes a unique design tool for this purpose.

In addition to the entertainment value of the stunt, this application has provided a demonstration of the validity of the HVOSM computer program in extreme, large amplitude motions.

\section{REFERENCES}

1. K. Ludvigsen, "Astro Spiral: The Ultimate Stunt," Motor Trend, April 1972.

2. R. R. McHenry a $\mathrm{n}$ d N. J. DeLevs. "Development of Analytical Aids for Minimization of Single Vehicle Accidents," CAL Report No. VJ-2251-V-10, July 1971.

3. R. R. McHenry, "Research in Automobile Dynamics - A Computer Simulation of General Three-Dimensional Motions," Society 
of Automotive Engineers Paper No. 710361, June 1971.

4. R. R. McHenry a $\mathrm{n} d$ N. J. Deleys,

"Vehicle Dynamics in Single Vehicle Accidents -

Validation and Extensions of a Computer
Simulation," CAL Report No. VJ-2251-V-3, December 1968.

5. R. R. McHenry, "Spiral Jump Apparatus," U.S. Patent No. 3,814,021, June 4, 1974.
This paper is subject to revision. Statements and opinions advanced in papers or discussion are the author's and are his responsibility, not the Society's; however, the paper has been edited by SAE for uniform styling and format. Discussion will be printed with the paper if it is published in SAE Transactions. For permission to publish this paper in full or in part, contact the SAE Publications Division.

Persons wishing to submit papers to be considered for presentation or publication through SAE should send the manuscript or a 300 word abstract of a proposed manuscript to: Secretary, Engineering Activities Board, SAE. 